\title{
Food Allergy: From Clinical Presentation to Management and Prevention
}

\author{
Saida Rezaković ${ }^{1, *}$, Marta Navratil ${ }^{2}$ and Kristina Žužul $\left.\right|^{3}$ \\ ${ }^{1}$ Policlinic "Eskulap" - Policlinic for Internal Medicine, Dermatovenerology, Neurology, Psychiatry, Surgery, \\ Gynecology, Urology, Otorhinolaryngology and Physical Medicine - Rehabilitation, Havidićeva 9/11, Zagreb, \\ Croatia \\ ${ }^{2}$ Department of Allergy and Pulmonology, Srebrnjak Children's Hospital, Srebrnjak 100, Zagreb, Croatia \\ ${ }^{3}$ Medical School, University of Zagreb, Šalata 4, Zagreb, Croatia
}

\begin{abstract}
Food allergy is an adverse immune-mediated pathological reaction directed toward proteins or glycoproteins in food. It affects the skin, gastrointestinal, respiratory and cardiovascular systems, resulting in a broad spectrum of diverse clinical presentations. Consequently, establishing a diagnosis can present a great challenge. The prevalence rate of food allergy is increasing, particularly in modern industrialized countries, and is becoming a significant public health problem. There is still no current treatment, and avoidance of suspected food allergens remains the most important treatment modality. However, in order to avoid unnecessary dietary restrictions, food hypersensitivity should be confirmed using allergy tests prior to introduction of elimination diet. In cases of validation of food allergy, avoiding suspected foods are recommended. Education of patients is the cornerstone of prevention and therapy; providing all relevant information on how to exclude specific foods from the patient's diet, as well as how to detect and manage allergic reactions, especially in severe cases like anaphylaxis. This review aims at presenting the clinical picture and diagnosis, as well as discussing current treatment and preventive strategies for different types of food allergies.
\end{abstract}

Keywords: Elimination diet, oral food challenge, food induced asthma, atopic dermatitis, food protein-induced enterocolitis syndrome, food protein-induced proctocolitis.

\section{INTRODUCTION}

Food allergy is defined as an adverse immune reaction to food proteins [1,2]. The most common food allergens responsible for allergic reactions include milk, egg, wheat, soy, peanuts, tree nuts, fish and shellfish [2-4]. It is estimated that food allergy affects approximately $5 \%$ of adults and $8 \%$ of children [3,5]. Numerous studies indicate an increase in prevalence worldwide, particularly in westernized countries $[4,5]$.

Many factors seem to have an impact on the incidence and prevalence of food allergy, including age, family history of atopic disease, local diet and lifestyle habits [4,5]. Possible risk factors for the development of food allergy include genetic predisposition, obesity, vitamin D insufficiency, increased hygiene, gender (male gender in children), race/ethnicity (increased among Asian and AfricanAmerican children), low intake of fatty acids (omega-3polyunsaturated fatty acids), as well as timing of exposure to foods [5-7]. In addition, other allergic conditions, such as asthma, present another risk factor for food allergy $[7,8]$.

*Address correspondence to this author at the Policlinic "Eskulap" - Policlinic for Internal Medicine, Dermatovenerology, Neurology, Psychiatry, Surgery, Gynecology, Urology, Otorhinolaryngology and Physical Medicine, Havidićeva 9/11, 10020 Zagreb, Croatia; Tel: 00385916553701; Fax: 0038516553701; E-mail: saida.rezakovic@gmail.com
The pathogenesis of food allergy is complex and not yet fully elucidated, although immunopathological factors, genetic predisposition and environmental factors seem to have a significant impact on the development of the disease [5,9,10]. Furthermore, immaturity of various components of the gut barrier and immune system in children, resulting in reduced efficiency of gastrointestinal mucosal barrier, could also be a significant contributing factor in pathogenesis, which would partly explain higher rates of food allergy in children $[5,10]$.

Based on immune reactions to foods and the involvement of $\lg E$ in their pathogenesis, food allergy can be categorized as IgE-mediated, cell-mediated or combined IgE- and cell-mediated [2,11,12]. $\lg \mathrm{E}$ mediated reaction is characterized by an acute onset of symptoms after ingestion of causative food allergen, usually within a few minutes to 2 hours of exposure $[2,5]$. The underlying pathophysiological mechanism consists of production of specific $\lg \mathrm{E}$ antibodies after exposure to the allergen, which become attached on tissue mast cells and blood basophils leading to sensitization [2,5]. Upon re-exposure, the causal food proteins bind to the food-specific IgE antibodies and trigger the release of pharmacologically active mediators, such as histamine, leukotrienes and prostaglandins, resulting in allergic reaction presented in different clinical patterns $[2,5]$. 
Skin symptoms such as urticaria or angioedema, and respiratory symptoms such as food-induced rhinitis or asthma are usually IgE-mediated [12]. Atopic dermatitis, on the other hand, is IgE-associated/cellmediated $[5,13]$. Gastrointestinal symptoms, which are mostly cell mediated, include food protein-induced enterocolitis syndrome, food protein-induced proctocolitis, food protein-induced enteropathy and eosinophilic gastrointestinal disorders. [2,12]. Delayed non-lgE-mediated food allergy primarily affects the gastrointestinal system. Unfortunately, far less is known of these pathophysiological mechanisms than IgE-mediated food hypersensitivities. These reactions are mediated by allergen-specific cellular immune responses, resulting in production of various proinflammatory cytokines including tumor necrosis factor (TNF)- $\alpha$ and IL-13, which increase intestinal epithelial cell permeability, alter intestinal function and enable the resorption of undigested food antigens $[11,12]$.

In general, clinical course, as well as the persistence of food allergy, differs greatly, depending on the specific food allergen. Food allergies to milk, egg, wheat, and soy that usually occur during childhood are commonly outgrown by the age of 3 , while allergies to fish, shellfish, peanuts and tree nuts tend to persist into adulthood $[4,7,14,15]$. It is estimated that only $20 \%$ of children with allergy to peanuts and $9 \%$ with tree nut allergy will develop tolerance $[16,17]$.

The aim of this review is to present diverse clinical presentation of food allergy, and to discuss diagnostic procedures, preventive measures and management strategies, in order to detect this disorder, minimise clinical symptoms and exacerbations, and finally improve the quality of life of patients.

\section{CLINICAL PRESENTATION}

Considering that food allergies can affect various organs, including the skin, gastrointestinal, respiratory, and cardiovascular system, symptoms include a broad spectrum of different clinical patterns [5,11]. In addition, there are a number of conditions that can mimic food allergies, including toxic reactions induced by some foods, for instance rhinorrhea provoked by consumption of spicy foods [5].

Food allergies can range from acute and possibly life-threatening reactions such as anaphylaxis, to chronic conditions such as atopic dermatitis [2]. Furthermore, besides the physical signs of the disease, food allergy affects the quality of life, and presents significant psychological burden to patients, particularly children $[5,18,19]$. In the following section, the most common clinical presentations of food allergy will be discussed.

\section{Respiratory Symptoms}

Upper and lower respiratory tract symptoms induced by food allergens are IgE-mediated. They commonly present as rhinoconjunctivitis, nasal congestion, rhinorrhea, sneezing and pruritus, or as food-induced asthma which is provoked by the inhalation of small particles of causative food released during cooking or food preparation $[3,9]$. Food-induced asthma can also be work-related, such as bakers' asthma, one of the most common forms of occupational asthma, where symptoms occur as a result of inhalation of the offending food allergen, while ingestion of the same allergen does not lead to allergic reactions $[3,4,9]$.

It should be noted that food induced rhinoconjunctivitis and/or asthma are rarely the only clinical symptoms of food allergy, thus they tend to be a part of systemic reaction [3], except in cases of occupational respiratory disorders $[3,4]$.

\section{Gastrointestinal Symptoms}

Food allergy can also present with gastrointestinal symptoms, in an acute or delayed manifestation [4]. Acute IgE-mediated reactions include anaphylaxis or an immediate gastrointestinal allergy, characterized by rapid onset of diarrhea, emesis and abdominal pain, developing soon after consumption of offending food [4]. Delayed manifestations include celiac disease, food protein-induced enterocolitis syndrome, food proteininduced proctocolitis, food protein-induced enteropathy and eosinophilic gastrointestinal disorders $[9,12]$.

Celiac disease and the related skin disorder dermatitis herpetiformis can also be considered food allergies because of an immune response to gluten [20]. This chronic autoimmune disorder is the most common genetically related food intolerance. Clinical presentation is very variable and often asymptomatic, but can include diarrhea, bloating, abnormal stretching of the abdomen, malnutrition, and weight loss $[4,9,20]$. Dermatitis herpetiformis, a classic skin manifestation of celiac disease, is characterized by pruritus and blistering skin rash that involves elbows, knees, and buttocks, commonly occurring in teenagers or adults [20]. 
Food protein-induced enterocolitis syndrome is a non-IgE-mediated food allergy, presumably T-cell mediated, characterized by repetitive vomiting and diarrhea at least 2-6 hours after ingestion of the triggering food $[2,12,21,22]$. In more severe clinical forms, infants may experience severe vomiting and diarrhea, leading to dehydration, hypotension, lethargy, and acidosis [22]. Symptoms usually occur before 9 months of age, with the peak incidence in the first 3 months of life $[9,21]$. The most common causative food allergens include milk and soy, although some solid foods might also be triggering foods, such as cereals, vegetables, and poultry [2,9,21,23-25]. Symptoms caused by solid foods such as cereal grains commonly develop in older infants [24].

Food protein-induced proctocolitis is characterized by blood-streaked stools with or without diarrhea, presenting in the first few months of life, usually in breastfed infants aged between 2 and 8 weeks, and is most frequently triggered by cow's milk and soy [10]. Symptoms can be also triggered by exposure to causal food allergens through maternal breast milk $[10,26]$. Besides these clinical symptoms, infants appear healthy, and do not develop blood loss-associated complications, such as anemia [2,25]. Symptoms usually resolve by 1 year of age [26].

Food protein-induced enteropathy is characterized by chronic diarrhea, malabsorption, and weight loss. The disorder most frequently occurs during the first several months of life, and is commonly induced by milk, soy, egg, wheat, rice, chicken or fish $[11,12]$.

Allergic eosinophilic gastroenteritis is another gastrointestinal manifestation of food allergy. This clinical entity is thought to be caused by mixed immunologic mechanisms (IgE- and T-cell-mediated) $[3,9,11]$. Patients with allergic eosinophilic gastroenteritis have chronic symptoms that usually develop after ingestion of offending food, and include severe reflux, abdominal pain, vomiting, dysphagia, and diarrhea [9]. Resolution of symptoms can be observed soon after the elimination of the causal food.

\section{Skin Symptoms}

Skin symptoms are among the most common manifestations of food allergy, frequently presenting as urticaria, angioedema and atopic dermatitis [3]. Urticaria is an acute, lgE-mediated disorder characterized by sudden local swelling in superficial dermis, presented as erythematous, smooth, slightly elevated and sharply-demarcated plaques or papules accompanied by pruritus [3]. Angioedema presents as asymmetric rapid swelling of the deep dermis, subcutaneous or submucosal tissue, commonly localized in periorbital or perioral area, accompanied by burning sensation and pain [3].

Atopic dermatitis (AD) is a common chronic, inflammatory skin disorder, triggered by a combination of IgE and cell-mediated processes. [2]. Food allergens have been identified as possible triggering factors for the development of eczema flare-ups and aggravation of this chronic relapsing dermatosis. It is estimated that approximately $35 \%$ of children with moderate or severe atopic dermatitis have food allergies [5]. Early onset of eczema, usually before 12 months of age, is considered to be more likely associated with concurrent food allergies [2]. Foods responsible for aggravation of atopic dermatitis symptoms can vary with age. In younger children, eggs, cow's milk, peanut, and soy are the most common triggering food allergens, while in older children, the main causative agents are tree nuts, wheat, fish, and shellfish. [27,28].

In addition, allergies to pollen-related foods are more frequent in older children, and therefore, possible causative foods include apple, carrot, celery, and hazelnut $[13,29]$. In these subsets of patients, avoiding suspected foods significantly improves clinical symptoms and decreases exacerbation rates. Nevertheless, it should be emphasized that although it is well known that food allergens can aggravate eczema symptoms, not all patients with $A D$ suffer from food allergy [5]. Patients with $A D$ can also have noneczematous reactions that are usually $\mathrm{lgE}$ mediated, commonly occuring within 2 hours of exposure, and presenting with urticaria, angioedema or diarrhea $[13,30]$.

\section{Anaphylaxis}

The most severe adverse reaction is anaphylaxis, multiorgan rapidly progressive lgE-mediated hypersensitivity, which can potentially be life threatening [2,11]. The onset is rapid, often within the seconds to minutes of food ingestion [4]. It affects multiple organ systems, presenting in a variety of symptoms including cutaneous manifestations such as urticaria, angioedema and pruritus, as well as respiratory symptoms including rhinorrhea, sneezing, stridor, congestion, dyspnea, chest tightness, and cyanosis [4]. Furthermore, gastrointestinal symptoms may include nausea, vomiting, abdominal cramps and 
diarrhea, while cardiovascular symptoms present as tachycardia, arrhythmia, syncope, hypotension, and shock [4].

Concomitant asthma, peanut, tree nut, and seafood allergies are additional risk factors associated with a more severe clinical course of anaphylaxis and potentially fatal outcome [4,9,31]. Aggressive and prompt therapeutic approach is necessary. Considering specific food allergens commonly associated with this severe allergic reaction, it is estimated that peanuts and tree nuts account for $80 \%$ of food-provoked fatal anaphylaxis cases [2].

Food-associated, exercise-induced anaphylaxis is another relatively rare and potentially life threatening condition [4,32]. It is characterized by development of anaphylaxis after eating a specific sensitizing food and engaging in physical activity soon after the time of ingestion $[4,32]$.

\section{Oral Allergy Syndrome}

The oral allergy syndrome is also referred to as pollen-food allergy syndrome, since it is caused by cross reacting allergens found both in pollen and raw fruits and vegetables $[4,12]$. The syndrome occurs in approximately $20 \%-70 \%$ of pollen-allergic patients after ingestion of certain fresh fruits and vegetables [3]. It is characterized by a rapid onset of localized oral pruritus accompanied by tingling and edema of the oral mucosa $[3,9,33]$. Typical examples of this cross-reactivity patterns include development of symptoms in birchallergic patients after eating an apple, cherry, pear, potato, carrot, celery, or kiwi, or occurrence of symptoms in ragweed-allergic patients after consuming melons or bananas $[3,4]$.

\section{Latex-Fruit Syndrome}

Latex-fruit syndrome is defined as an association of latex allergy and allergy to plant foods, affecting up to $50 \%$ of patients with latex allergy $[34,35]$. Crossreactivity is manifested by the allergic reaction in predisposed individuals after exposure to two different species, such as latex and plant-derived foods. It seems to be attributed to structural similarities between the two.

Clinical presentation of latex allergy is diverse, including allergic rhinitis and asthma, contact urticaria, eczema and xeroderma, or severe and possible lifethreatening systemic reactions such as anaphylaxis [36]. The most common foods involved include bananas, avocado, chestnut, kiwi, pineapple, mango, fig, strawberry and soy $[35,36]$. It is important to point out that latex-fruit syndrome, as may be presumed by its name, does not only refer to fruits, but to other plants as well, such as vegetables. This includes carrots, celery, potatoes, tomatoes, oregano and peppers, which can produce the same effect [36].

\section{DIAGNOSIS}

Diagnosing food allergy is frequently difficult and complicated, so it consequently requires careful and thorough medical and dietary history in order to exclude a variety of differential diagnoses [11]. Furthermore, in order to confirm a food allergy, certain diagnostic tests should be performed, including skin prick tests, food-specific IgE antibodies levels, and/or oral food challenge $[5,11]$. When taking medical history, emphasis should not only be placed on potential causal food, but also on other factors, including the quantity of ingested food, time of onset, course and duration of reaction, prior allergic reactions, and other possibly eliciting factors such as exercise [5,11]. Diagnostic procedures differ greatly, depending on underlying immunopathological mechanisms, as listed on Table 1.

In cases of IgE-mediated immune reactions to foods, skin prick testing and serum $\lg E$ are diagnostic tests that can provide an indication of the likelihood of allergic reaction with exposure to the food allergen $[2,29]$. Although skin prick test is usually the first line diagnostic procedure, it is estimated that approximately only one third of positive tests correlate with positive oral food challenge test, which is a gold standard in diagnosing food allergy [37]. The negative predictive value of this test is very high, and therefore, negative result can rule out IgE-mediated allergic hypersensitivity [11]. In contrast, since positive predictive value is low, a positive result is not a proof of food allergy, but can only suggest it [11]. Considering specific $\lg E$ measurement, this test is generally less sensitive than the skin prick test, with low positive predictive value; therefore there is usually a need for further diagnostic confirmation [13]. Nevertheless, higher $\lg \mathrm{E}$ levels are associated with more severe clinical symptoms, exacerbations and poorer prognosis than lower values $[4,18]$. The rate of decline in food specific $\lg E$ levels over time seems to positively correlate with the decrease in severity of clinical symptoms and exacerbations; thus it could be a predictive value for the development of tolerance $[4,38,39]$. Conclusively, it should be noted that the skin prick test and specific $\lg \mathrm{E}$ measurement do not have 
sufficient specificity and reliability to clinically prove the relevant hypersensitivity, or to be used as broad screening methods, but they are reliable in ruling out an IgE-mediated reaction $[4,11,40]$.

Diagnosing non-lgE-mediated reactions can truly be challenging considering there is no specific laboratory test available to detect these disorders and identify causative foods $[9,41]$. Since skin prick test responses or serum allergen-specific IgE antibody results are typically negative in these conditions, elimination diets as a diagnostic method or/and oral food challenge test are often required in order to pinpoint offending foods $[9,21,41]$.

Nevertheless, in some gastrointestinal non-lgEmediated allergic reactions such as celiac disease and allergic eosinophilic gastroenteritis, biopsy can help in establishing diagnosis [9]. Diagnosis of celiac disease is established by a biopsy specimen taken from the duodenal mucosa [42]. Additionally, elevated levels of endomysial, anti-tissue transglutaminase and antigliadin antibodies may help in confirming the diagnosis, but are commonly used for screening or monitoring the condition [42].

In case of food protein-induced proctocolitis, seeing that clinical features and laboratory tests are nonspecific, diagnosis is established based upon improvement of clinical symptoms following exclusion diet. However, in cases of unclear or atypical presentations, colonoscopy and a biopsy might be indicated in order to exclude other possible causes of rectal bleeding [43].
Diagnosis of food allergy in patients with atopic dermatitis includes in vivo (skin prick test) or/and in vitro testing (specific $\lg \mathrm{E}$ measurement) to explore $\lg \mathrm{E}$ mediated sensitization [13]. Foods that are tested as possible triggering factors are chosen according to patient clinical history [13]. Atopy patch test could also be an additional diagnostic tool in diagnosing the food allergy, particularly in those patients where standard allergy tests (skin prick test and specific lgE) failed to identify causative food allergens, as well as in cases of multiple food allergies $[44,45]$. Elimination diet of several weeks (4-6) might also have a diagnostic value, although it should be taken into consideration that clinical improvement might be due to the other factors besides diet, and therefore, relying only on these observations could result in unnecessary dietary restrictions [13]. Oral food challenge test is the most important diagnostic step and remains the "gold standard" in diagnosis of food allergy $[13,46]$. It is usually conducted if further validation of food allergy is required. For instance, given the high negative predictive value and low positive predictive value, negative prick tests can be helpful to exclude food allergy, but a positive test often needs to be confirmed by oral food challenge to confirm the diagnosis of food allergy $[13,47,48]$. Nevertheless, it should be noted that this diagnostic procedure presents a potential risk to a patient, considering severe adverse reaction that may occur [46]. Therefore, it should always be carried out in a hospital setting under close monitoring, where emergency medications and equipment to treat anaphylaxis are available [13].

Conclusively, in cases of positive allergy tests, avoidance of suspected food/foods should be initiated

Table 1: Classification of Food Allergy Based upon Immunopathological Mechanisms

\begin{tabular}{|l|l|l|l|}
\hline Immunopathology & $\begin{array}{l}\text { Onset of } \\
\text { symptoms }\end{array}$ & Disorder & Diagnostic procedure \\
\hline \hline IgE-mediated & acute & $\begin{array}{l}\text { - urticaria/angioedema } \\
- \text { rhinoconjunctivitis/asthma } \\
- \text { oral allergy syndrome } \\
- \text { latex-fruit syndrome } \\
\text { - anaphylaxis } \\
\text { - food-associated exercise-induced anaphylaxis }\end{array}$ & $\begin{array}{l}\text { - skin prick tests and/or specific serum IgE } \\
\text { assays } \\
- \text { trial elimination of the suspected food } \\
\text { allergen } \\
\text { - food challenge }\end{array}$ \\
\hline Cell-mediated & delayed & $\begin{array}{l}\text { - food protein-induced enterocolitis syndrome } \\
\text { - food protein-induced proctocolitis } \\
\text { - food protein-induced enteropathy }\end{array}$ & $\begin{array}{l}\text { - trial elimination of the suspected food } \\
\text { allergen }\end{array}$ \\
\hline $\begin{array}{l}\text { Mixed IgE- and } \\
\text { cell-mediated }\end{array}$ & delayed & $\begin{array}{l}\text { - atopic dermatitis } \\
\text { - eosinophilic gastrointestinal disorders }\end{array}$ & $\begin{array}{l}\text { - skin prick tests and/or specific serum IgE } \\
\text { assays } \\
\text {-- trial elimination of the suspected food } \\
\text { allergen } \\
\text { - food challenge }\end{array}$ \\
\hline
\end{tabular}


for a shorter period of time for diagnostic purpose, and in case of clinical improvement, oral food challenge should be considered as a final diagnostic procedure to confirm food allergy and institute elimination diet [13].

\section{MANAGEMENT AND PREVENTION}

The current approach to management of food allergy is focused on educating patients about the food allergen avoidance, as well as the proper use of emergency therapy such as administration of selfinjectable epinephrine in cases of unintended ingestion of casual food [2,5]. Considering the fact that adverse reactions to food can be serious and even life threatening, the patient has to be warned and educated to promptly react in these situations $[5,9,49]$. Occurrence of anaphylaxis requires prompt administration of epinephrine, antihistamines and corticosteroids as an adjunct therapy, aggressive fluid resuscitation and close monitoring [4].

Elimination diet and prolonged allergen avoidance of specific food is strongly encouraged only in cases of clear confirmation of food allergy, since the institution of dietary restrictions is often unnecessary, and can result in nutritional imbalances or even significant deficiencies $[2,5,46]$. In cases of confirmed celiac disease, introduction of gluten free diet, meaning strict avoidance of foods containing wheat, rye, barley, and spelt (oat), is obligatory [3]. It is important to emphasize that although the food allergen avoidance technique is usually effective, this preventive and therapeutic method may be difficult to apply in everyday life, considering many common food allergens are ubiquitous in the diet [50]. This may significantly disrupt everyday life and cause a major burden to children, as well as their families [50]. However, for a significant subset of patients, complete exclusion of the offending food is the only treatment modality. Therefore, education of a patient with food allergy is crucial in terms of avoidance of specific foods and reading ingredient labels on both food and non-food product labels, as many cosmetic products might contain offending allergen.

Moreover, patients who tend to have life-threatening allergic reactions such as angioedema or anaphylaxis should be strongly advised to keep an automatic epinephrine injection device available at all times [51]. The subset of patients with food-associated, exerciseinduced anaphylaxis should be advised to avoid food ingestion a few hours before physical activity [4]. Some research suggests that food preparation may affect allergenic potential of foods [11]. It seems that heating reduces the allergenicity of some foods such as milk and eggs; therefore, introducing extensively heated specific foods into the diet might provide tolerability in the subset of patients with hypersensitivity reactions to these foods $[5,11,46,52]$. Thermal processing is particularly recommended in cases of oral allergy syndrome, since these patients are able to ingest cooked food without developing symptoms [9,33]. However, for the variety of other foods, the heating process may not produce similar effect, as it does not reduce allergenicity for all foods [46]. Interestingly, some foods such as peanuts tend to become even more allergenic by thermal processing, for instance by roasting [53,54]. Considering introduction of solid foods to children, prolonged avoidance of solids has not proven to be a beneficial preventive measure [9]. Nevertheless, considering higher allergenic potential of some foods, including egg, peanut, tree nuts, fish, and seafood, they should be introduced with caution, one by one, and in smaller amounts [44].

Active prevention in terms of introduction of prebiotics, probiotics, synbiotics, and bacterial lysates might be promising, but data demonstrating potentially beneficial effects are still conflicting and inconclusive $[5,55]$. Finally, future development of immunotherapy for food allergy treatment, providing a level of desensitization, might be a new promising option [2].

\section{CONCLUSION}

Food allergy is a common hypersensitivity in childhood. This disorder comprise of diverse group of clinical syndromes ranging from mild to severe and lifethreatening reactions. Understanding diversity in clinical manifestations, as well as complex and different underlying pathophysiological mechanisms, is the most important step in diagnosing and providing successful treatment. Considering food allergy is frequently misdiagnosed, establishing an accurate diagnosis and recognition of potential food allergens as causative agents is vital, in order to minimize the risk of development of clinical symptoms and to improve the patients' quality of life. Future research efforts should be focused on improving diagnostic approaches, as well as immunomodulatory treatment strategies, since avoidance of specific foods as the main current treatment option can be limiting and difficult to implement in everyday life.

\section{CONFLICT OF INTEREST STATEMENT}

None declared. 


\section{REFERENCES}

[1] Johansson SG, Bieber $\mathrm{T}$, Dahl $\mathrm{R}$, et al. Revised nomenclature for allergy for global use: report of the Nomenclature Review Committee of the World Allergy Organization, October 2003. J Allergy Clin Immunol 2004; 113: 832-836. http://dx.doi.org/10.1016/j.jaci.2003.12.591

Tang J, Sampson HA. Food allergy: recent advances in pathophysiology and treatment. Allergy Asthma Immunol Res 2009; 1(1): 19-29.

http://dx.doi.org/10.4168/aair.2009.1.1.19

[3] Mansoor DK, Sharma HP. Clinical presentations of food allergy. Pediatr Clin North Am 2011; 58(2): 315-326. http://dx.doi.org/10.1016/j.pcl.2011.02.008

[4] Davis CM. Food allergies: clinical manifestations, diagnosis, and management. Curr Probl Pediatr Adolesc Health Care 2009; 39(10): 236-254. http://dx.doi.org/10.1016/i.cppeds.2009.09.003

[5] Sicherer SH, Sampson HA. Food allergy: Epidemiology, pathogenesis, diagnosis, and treatment. J Allergy Clin Immunol 2014; 133(2): 291-307. http://dx.doi.org/10.1016/i.jaci.2013.11.020

[6] Lack G. Update on risk factors for food allergy. J Allergy Clin Immunol 2012; 129: 1187-1197. http://dx.doi.org/10.1016/j.jaci.2012.02.036

[7] Sicherer SH, Munoz-Furlong A, Sampson HA. Prevalence of seafood allergy in the United States determined by a random telephone survey. J Allergy Clin Immunol 2004; 114: 159165.

http://dx.doi.org/10.1016/j.jaci.2004.04.018

[8] Liu AH, Jaramillo R, Sicherer $\mathrm{SH}$, et al. National prevalence and risk factors for food allergy and relationship to asthma: results from the National Health and Nutrition Examination Survey 2005-2006. J Allergy Clin Immunol 2010; 126: 798806

http://dx.doi.org/10.1016/i.jaci.2010.07.026

[9] Sicherer SH. Manifestations of food allergy: evaluation and management. Am Fam Physician. 1999; 59(2): 415-424, 429-430.

[10] Sicherer SH: Clinical aspects of gastrointestinal food allergy in childhood. Pediatrics 2003; 111: 1609-1616.

[11] Dupont C. Food allergy: recent advances in pathophysiology and diagnosis. Ann Nutr Metab 2011; 59: 8-18. http://dx.doi.org/10.1159/000334145

[12] Morita H, Nomura I, Matsuda A, Saito H, Matsumoto K. Gastrointestinal food allergy in infants. Allergol Int 2013; 62(3): 297-307.

http://dx.doi.org/10.2332/allergolint.13-RA-0542

[13] Bergmann MM, Caubet JC, Boguniewicz M, Eigenmann PA. Evaluation of food allergy in patients with atopic dermatitis. $J$ Allergy Clin Immunol Pract 2013; 1(1): 22-28.

http://dx.doi.org/10.1016/i.jaip.2012.11.005

[14] Skripak JM, Matsui EC, Mudd K, Wood RA. The natural history of IgE-mediated cow's milk allergy. J Allergy Clin Immunol 2007; 120: 1172-1177.

http://dx.doi.org/10.1016/j.jaci.2007.08.023

[15] Savage JH, Matsui EC, Skripak JM, Wood RA. The natural history of egg allergy. J Allergy Clin Immunol 2007; 120: 1413-1417. http://dx.doi.org/10.1016/j.jaci.2007.09.040

[16] Skolnick HS, Conover-Walker MK, Koerner CB, Sampson HA, Burks W, Wood RA. The natural history of peanut allergy. J Allergy Clin Immunol 2001; 107: 367-374. http://dx.doi.org/10.1067/mai.2001.112129

[17] Fleischer DM, Conover-Walker MK, Matsui EC, Wood RA. The natural history of tree nut allergy. J Allergy Clin Immunol 2005; 116: 1087-1093. http://dx.doi.org/10.1016/j.jaci.2005.09.002
[18] Neuman-Sunshine DL, Eckman JA, Keet CA, et al. The natural history of persistent peanut allergy. Ann Allergy Asthma Immunol 2012; 108: 326-331. http://dx.doi.org/10.1016/j.anai.2011.11.010

[19] Resnick ES, Pieretti MM, Maloney J, Noone S, MunozFurlong A, Sicherer SH. Development of a questionnaire to measure quality of life in adolescents with food allergy: the FAQL-teen. Ann Allergy Asthma Immunol 2010; 105: 364368.

http://dx.doi.org/10.1016/j.anai.2010.09.006

[20] Guandalini S, Setty M. Celiac disease. Curr Opin Gastroenterol 2008; 24(6): 707-712. http://dx.doi.org/10.1097/MOG.0b013e32830ł4527

[21] Caubet JC, Ford LS, Sickles L, et al. Clinical features and resolution of food protein-induced enterocolitis syndrome: 10 year experience. J Allergy Clin Immunol 2014; 134(2): 382389.

http://dx.doi.org/10.1016/.j.jaci.2014.04.008

[22] Sicherer SH. Food protein-induced enterocolitis syndrome: case presentations and management lessons. J Allergy Clin Immunol 2005; 115(1): 149-156. http://dx.doi.org/10.1016/j.jaci.2004.09.033

[23] Levy Y, Danon YL. Food protein-induced enterocolitis syndrome-not only due to cow's milk and soy. Pediatr Allergy Immunol 2003; 14: 325-329. http://dx.doi.org/10.1034/j.1399-3038.2003.00039.x

[24] Bruijnzeel KC, Ortolani C, Aas K et al. Adverse reactions to food. European academy of allergology and clinical immunology subcommittee. Allergy 1995; 50: 623-635. http://dx.doi.org/10.1111/j.1398-9995.1995.tb02579.x

[25] Nowak-Wegrzyn A, Muraro A. Food protein-induced enterocolitis syndrome. Curr Opin Allergy Clin Immunol 2009; 9: $371-377$

\section{http://dx.doi.org/10.1097/ACl.0b013e32832d6315}

[26] Lake AM. Food-induced eosinophilic proctocolitis. J Pediatr Gastroenterol Nutr 2000; 30: 58-60. http://dx.doi.org/10.1097/00005176-200001001-00009

[27] Kim J, Kwon J, Noh G, Lee SS. The effects of elimination diet on nutritional status in subjects with atopic dermatitis. Nutr Res Pract 2013; 7(6): 488-494

http://dx.doi.org/10.4162/nrp.2013.7.6.488

[28] Kim JS. Pediatric atopic dermatitis: the importance of food allergens. Semin Cutan Med Surg 2008; 27(2): 156-160. http://dx.doi.org/10.1016/i.sder.2008.05.003

[29] Breuer K, Wulf A, Constien A, Tetau D, Kapp A, Werfel T. Birch pollen related food as a provocation factor of allergic symptoms in children with atopic eczema/dermatitis syndrome. Allergy 2004; 59: 988-994.

http://dx.doi.org/10.1111/j.1398-9995.2004.00493.x

[30] Sampson HA. The evaluation and management of food allergy in atopic dermatitis. Clin Dermatol 2003; 21: 183-192. http://dx.doi.org/10.1016/S0738-081X(02)00363-2

[31] Sampson HA, Mendelson LM, Rosen JP. Fatal and near-fatal anaphylactic reactions to food in children and adolescents. $N$ Engl J Med 1992; 327: 380-384. http://dx.doi.org/10.1056/NEJM199208063270603

[32] Barg W, Medrala W, Wolanczyk-Medrala A. Exerciseinduced anaphylaxis: an update on diagnosis and treatment. Curr Allergy Asthma Rep 2011; 11(1): 45-51. http://dx.doi.org/10.1007/s11882-010-0150-y

[33] Kelava N, Lugović-Mihić L, Duvancić T, Romić R, Situm M. Oral allergy syndrome - the need of a multidisciplinary approach. Acta Clin Croat 2014; 53(2): 210-219.

[34] Blanco C, Carrillo T, Castillo R, Quiralte J, Cuevas M. Latex allergy: clinical features and cross-reactivity with fruits. Ann Allergy 1994; 73: 309-314.

[35] Brehler R, Theissen U, Mohr C, Luger T. Latex-fruit syndrome: frequency of cross-reacting $\operatorname{lgE}$ antibodies. Allergy 1997; 52(4): 404-410.

http://dx.doi.org/10.1111/j.1398-9995.1997.tb01019.x 
[36] Beezhold DH, Sussman GL, Liss, GM, Chang NS. Latex allergy can induce clinical reactions to specific foods. Clin Exp Allergy 1996; 26: 416-422. http://dx.doi.org/10.1046/j.1365-2222.1996.d01-334.x

[37] Lee SS, Noh G, Lee KY. Clinical application of histamine prick test for food challenge in atopic dermatitis. Journal of Korean Medical Science 2001; 16: 276-282. http://dx.doi.org/10.3346/jkms.2001.16.3.276

[38] Perry TT, Matsui EC, Kay Conover-Walker M, Wood RA. The relationship of allergen-specific $\mathrm{IgE}$ levels and oral food challenge outcome. J Allergy Clin Immunol 2004; 114: 144149.

http://dx.doi.org/10.1016/j.jaci.2004.04.009

[39] Boyano Martinez T, Garcia-Ara C, Diaz-Pena JM, Munoz FM, Garcia Sanchez G, Esteban MM. Validity of specific IgE antibodies in children with egg allergy. Clin Exp Allergy 2001; 31: 1464-1469. http://dx.doi.org/10.1046/j.1365-2222.2001.01175.x

[40] Hill DJ, Heine RG, Hosking CS. The diagnostic value of skin prick testing in children with food allergy. Pediatr Allergy Immunol 2004; 15: 435-441.

http://dx.doi.org/10.1111/j.1399-3038.2004.00188.x

[41] Nomura I, Morita $\mathrm{H}$, Hosokawa $\mathrm{S}$, et al. Four distinct subtypes of non-lgE-mediated gastrointestinal food allergies in neonates and infants, distinguished by their initial symptoms. J Allergy Clin Immunol 2011; 127: 685-688. http://dx.doi.org/10.1016/j.jaci.2011.01.019

[42] Hill P, Austin A, Forsyth J, Holmes G. British Society of Gastroenterology guidelines on the diagnosis and management of coeliac disease. Gut 2014. http://dx.doi.org/10.1136/gutjnl-2014-308420

[43] Rothenberg ME: Eosinophilic gastrointestinal disorders (EGID). J Allergy Clin Immunol 2004; 113(1): 11-28. http://dx.doi.org/10.1016/j.jaci.2003.10.047

[44] Turjanmaa K, Darsow U, Niggemann B, Rance F, Vanto T, Werfel T. EAACI/GA2LEN position paper: present status of the atopy patch test. Allergy 2006; 61: 1377-1384. http://dx.doi.org/10.1111/j.1398-9995.2006.01136.x

[45] Darsow U, Laifaoui J, Kerschenlohr K, et al. The prevalence of positive reactions in the atopy patch test with aeroallergens and food allergens in subjects with atopic eczema: a European multicenter study. Allergy 2004; 59: 1318-1325.

http://dx.doi.org/10.1111/j.1398-9995.2004.00556.x
[46] Bloom KA, Huang FR, Bencharitiwong R, et al. Effect of Heat Treatment on Milk and Egg Proteins Allergenicity. Pediatr Allergy Immunol 2014. http://dx.doi.org/10.1111/pai.12283

[47] Bock SA, Lee WY, Remigio L, Holst A, May CD. Appraisal of skin tests with food extracts for diagnosis of food hypersensitivity. Clin Allergy 1978; 8: 559-564. http://dx.doi.org/10.1111/j.1365-2222.1978.tb01509.x

[48] Sampson HA, Albergo R. Comparison of results of skin tests RAST, and double-blind, placebo-controlled food challenges in children with atopic dermatitis. J Allergy Clin Immunol 1984; 74: 26-33. http://dx.doi.org/10.1016/0091-6749(84)90083-6

[49] Jones SM, Burks AW. The changing CARE for patients with food allergy. J Allergy Clin Immunol 2013; 131: 3-11. http://dx.doi.org/10.1016/j.jaci.2012.11.012

[50] Sicherer SH, Simons FE. Self-injectable epinephrine for firstaid management of anaphylaxis. Pediatrics 2007; 119: 638646.

http://dx.doi.org/10.1542/peds.2006-3689

[51] Yu JW, Kagan R, Verreault N, et al. A. Accidental ingestions in children with peanut allergy. J Allergy Clin Immunol 2006; 118: 466-472. http://dx.doi.org/10.1016/j.jaci.2006.04.024

[52] Nowak-Wegrzyn A, Sampson HA. Future therapies for food allergies. J Allergy Clin Immunol 2011; 127: 558-573. http://dx.doi.org/10.1016/j.jaci.2010.12.1098

[53] Maleki SJ, Hurlburt BK. Structural and functional alterations in major peanut allergens caused by thermal processing. $J$ AOAC Int 2004; 87: 1475-1479.

[54] Gruber P, Becker WM, Hofmann T. Influence of the maillard reaction on the allergenicity of $\mathrm{rAra} h 2$, a recombinant major allergen from peanut (Arachis hypogaea), its major epitopes, and peanut agglutinin. J Agric Food Chem 2005; 53: 22892296.

http://dx.doi.org/10.1021/jf048398w

[55] Pfefferle PI, Prescott SL, Kopp M. Microbial influence on tolerance and opportunities for intervention with prebiotics/probiotics and bacterial lysates. J Allergy Clin Immunol 2013; 131: 1453-1463. http://dx.doi.org/10.1016/j.jaci.2013.03.020 